\title{
The College Library
}

During the past six months the College Library has continued to receive many gifts of books. The Librarian wishes to thank Dr W. A. Roper for donating the valuable collection left by his late father, Dr W. F. Roper, as well as the following Members for copies of their own works.

Dr S. Bloch Soviet Psychiatric Abuse: The Shadow Over the World

Lt Col M. Asghar Chaudhri Introduction to Psychiatry Dr D. Chiswick Prosecution of the Mentally Disturbed Professor A. W. Clare Let's Talk About Me Psychiatry and General Practice In the Psychiatrist's Chair

Professor J. Copeland The Mind and Mood of Aging Professor D. R. Davis An Introduction to Psychopathology Dr J. Evans Adolescent and Pre-Adolescent Psychiatry Professor P. Flor-Henry Cerebral Basis of Psychopathology
Dr W. A. Heaton-Ward Mental Handicap

Professor D. W. K. Kay Handbook of Studies on Psychiatry and Old Age

Dr J. S. Madden A Guide to Alcohol and Drug Dependence

Dr B. O'Shea Essays in Psychiatry

Dr H. Petursson and Professor M. Lader Dependence on Tranquillisers

Dr N. Sartorius Source Book of Geriatric A ssessment

Professor M. Shepherd The Spectrum of Psychiatric Research

Professor M. Sim Guide to Psychiatry

Professor A. C. P. Sims Lecture Notes on Behavioural Sciences

Dr A. C. R. Skynner Families and How to Survive Them

Dr A. Stedeford Facing Death: Families and Professionals

Dr D. Steinberg The Clinical Psychiatry of Adolescence

Professor F. A. Whitlock Drugs, Morality and the Law

\section{Forthcoming Events}

A one-day symposium on 'Eating Disorders' will be held at the Cornwall Postgraduate Centre, Royal Cornwall Hospital (Treliske), Truro, Cornwall, on 27 March 1985. Programme and further information: Dr G. Tomlinson, St Lawrence's Hospital, Bodmin, Cornwall.

An international symposium on 'Disorders of Eating Behaviour: A Psychoneuroendocrine Approach', organized by the University of Pavia, School of Endocrinology, will be held in Pavia, Italy from 12 to 15 September 1985. Information: Professor Ettore Ferrari, Clinica Medica 1, Policlinico S. Matteo, 27100 Pavia, Italy.
A one-day MRCPsych Final Examination Workshop will be held on 30 March 1985 at St Crispin Hospital, Duston, Northampton. Limited places will be available. Information: Dr H. Ghadiali or Dr K. Dwivedi, St Crispin Hospital, Duston, Northampton NN5 6UN (telephone: Northampton (0604) 52323).

The First European Workshop on Transcultural Group Analysis, organized by the European Association for Transcultural Analysis of Groups, will be held in Maastricht, Holland from 25 to 28 July 1985. Information: Dr Malcolm Pines, Tavistock Clinic, 120 Belsize Lane, London NW3 5BA.

Misnomer or 'Don't Just Lie There, Do Something!'

You call me 'shrink', I wonder why

for my appointed task is opposite. I try

to loosen and free the secret self, expand, enliven it, let egos fly.

You resist, prefer to keep your tread upon familiar ground, nor wish instead to risk the wider world and new departures. Yet, caged within your shrinking head,

a spirit springs eager still to fly.

So think the brave thoughts in your head, sing songs unsung, shout words unsaid, face challenges unmet, the girls escaped your bed!

Come take the offer now before you're dead!

\section{KEN MORRICE}

